DOI: $10.5455 / 2320-1770$. ijrcog20130933

Case Report

\title{
A rare case of primary parasitic leiomyoma
}

\section{Sreelatha S*, Ashok Kumar, Vedavathy Nayak, Sahana Punneshetty, Nirmala Hanji}

Department of Obstetrics \& Gynecology, ESICMC \& PGIMSR, Bangalore, Karnataka, India

Received: 19 April 2013

Accepted: 10 May 2013

\section{*Correspondence:}

Dr. Sreelatha S,

E-mail: dr.sreelatha2011@gmail.com

(C) 2013 Sreelatha $\mathrm{S}$ et al. This is an open-access article distributed under the terms of the Creative Commons Attribution Non-Commercial License, which permits unrestricted non-commercial use, distribution, and reproduction in any medium, provided the original work is properly cited.

\section{ABSTRACT}

We report a rare case of a parasitic fibroid in a 42 year old woman who presented with mass per abdomen and backache. Ultrasound showed a mass suggestive of posterior wall fibroid. Laparotomy revealed a parasitic fibroid densely adherent to the omentum and extending retroperitoneally. Histopathological findings were consistent with leiomyoma.

Keywords: Primary parasitic leiomyoma, Abdominal hysterectomy

\section{INTRODUCTION}

Uterine leiomyomas are one of the most common tumors found in women of reproductive age. Uterine leiomyomas affect 20 to $30 \%$ of women older than 35 years, and their incidence may be on the rise since many women are postponing their reproductive careers. ${ }^{1}$ Extrauterine leiomyomas are rare, benign, and may arise in any anatomic sites. Their unusual growth pattern may even mimic malignancy and can result in a clinical dilemma. Occasionally, uterine leiomyomas become adherent to surrounding structures. They also develop an auxiliary blood supply, and lose their original attachment to the uterus, thus becoming 'parasitic'. Parasitic leiomyomas have been found in the remnants of a previous hysterectomy or laparoscopic myomectomy especially when morcellators were used for retrieval. ${ }^{2,3}$ Parasitic myomas are rare but have been reported in literature. These could be myomas detached from the uterus, which have taken blood supply from adjacent organs or could be retained myoma fragments.

\section{CASE REPORT}

A 42 year old multiparous woman presented to us with complaints of mass per abdomen and backache of 3 months duration. Other than a tubal ligation surgery, she did not give history of any surgeries in the past. On examination per abdomen the mass was 16 weeks gravid uterus size with restricted mobility. On pervaginal examination, the same mass was felt through the pouch of Doughlas. Ultrasound revealed a $15 \times 11 \mathrm{~cm}$ mass in the pouch of Doughlas suggestive of posterior wall fibroid. On laparotomy, the uterus was bulky. A 15 X $11 \mathrm{~cm}$ mass was seen separate from the uterus and was completely covered by and densely adherent to the omentum. It was also extending retroperitoneally. Total abdominal hysterectomy with bilateral salpingo-oopherectomy with excision of the mass was done. Because of dense adhesions, excision of the mass was difficult and was removed piecemeal but completely. Total weight of the mass was $400 \mathrm{~g}$. Histopathological findings were consistent with Leiomyoma. The patient had an uneventful post operative period and was discharged on the $8^{\text {th }}$ day.

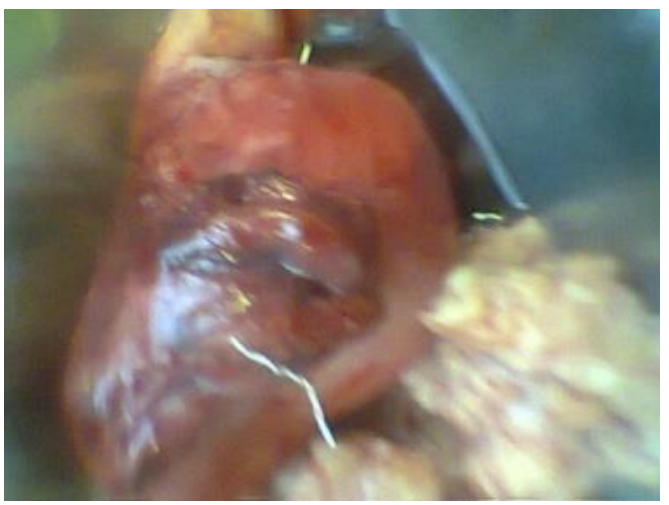

Figure 1: Uterus with parasitic fibroid. 


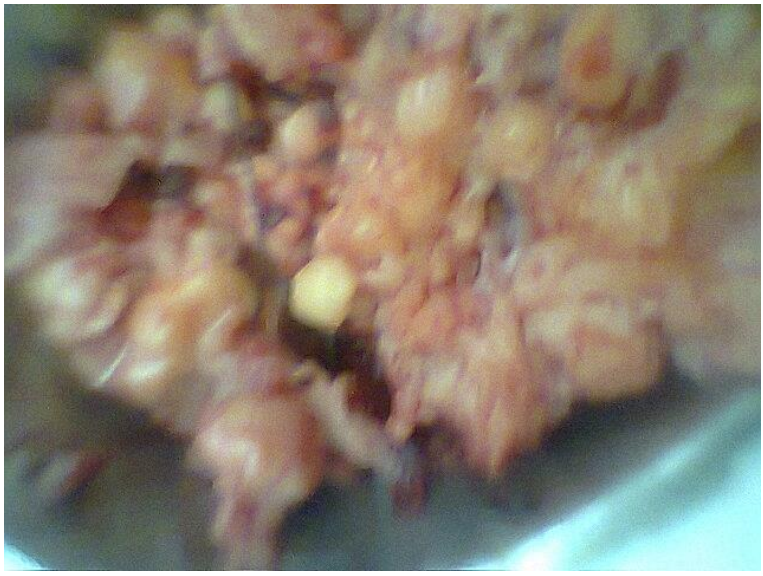

Figure 2: Parasitic fibroid removed piece meal.

\section{DISCUSSION}

Leiomyomas are benign smooth muscle tumors clinically apparent in $20-25 \%$ of women of reproductive age. As leiomyomas enlarge, they may outgrow their blood supply, resulting in various types of degeneration: hyaline or myxoid degeneration, calcification, cystic degeneration, or red degeneration. ${ }^{4}$ In general, hyaline degeneration is the most common (63\%) form of degeneration, while the others occur less frequently, such as myxomatous changes (13\%), calcification (8\%), mucoid changes $(6 \%)$, cystic degeneration (4\%), red degeneration $(3 \%)$, and fatty changes $(3 \%) .^{5}$ There are reports of myomas that have spontaneously lost their connections to the uterus and parasitized other blood supplies. Occasionally, pedunculated subserosal leiomyomas can be twisted on the uterine pedicle, and become detached in the peritoneal cavity. Such leiomyomas are referred to as "parasitic leiomyomas". This tumor survives by revascularization from adjacent structures. ${ }^{6}$ However, sometimes the tumor can adhere to the surrounding structures. The initial pedunculated fibroids likely develop premenopausally, whereas the parasitic leiomyoma may become clinically evident either before or after menopause. ${ }^{7}$ Parasitic myomas are rare occurrences, which can prove to be a diagnostic dilemma and may even be present in the acute setting or even mimic a malignancy.

Nowadays advances in retrieval systems have made laparoscopic myomectomy a feasible option, irrespective of size, site or number of myomas. ${ }^{8}$ There are increasing reports of parasitic fibroids being recognized after laparoscopic myomectomy, especially in those cases where tumors are morcellated for removal.

Parasitic leiomyomas, though infrequent, are most commonly located in the broad ligament, pelvic peritoneum, cul-de-sac, and omentum. ${ }^{9}$ Kho and Nezhathave one of the largest series in the literature of parasitic myomas, they attempted to determine their cause, associations, and risk factors. ${ }^{10}$ Leiomyomas are rarely found in postmenopausal women because their growth is thought to be estrogen dependent. Lumsden et al and Vollenhoven et al suggested that an association of polypeptide growth factors, such as platelet derived growth factors (PDGF), transforming growth factors, andvascular endothelial growth factors (VEGF), stimulated the growth of leiomyomas. ${ }^{11}$

Cucinella et alrecently reported, on their series of parasitic myomas, that they identified four cases over a three-year period. Electric morcellators were used in 423 cases and the overall prevalence of developing parasitic myoma was reported at 0.9 and $1.2 \%$ for those who had laparoscopic myomectomies. ${ }^{12}$ There are also cases in the literature in which parasitic myomas have been found attached to the bowel and anterior abdominal wall after laparoscopic myomectomy. ${ }^{13,14}$

\section{CONCLUSION}

It is likely that primary parasitic myomas will continue to be rare occurrences, however, parasitic myomas, which are iatrogenically caused, may be diagnosed more commonly in this laparoscopic era.

\section{REFERENCES}

1. Van Katwijk C, Peters LLH. Clinical aspects of pregnancy after the age of 35 years: a review of the literature. Hum Reprod Update. 1998;4(2):185-94.

2. Paul PG, Koshy AK. Multiple peritoneal parasitic myomas after laparoscopic myomectomy and morcellation. Fertil Steril.2006;85:492-493.

3. Moon HS, Koo JS, Park SH, Park GS, Choi JG, Kim SG. Parasitic leiomyoma in the abdominal wall after laparoscopic myomectomy. Fertil Steril. 2008;90:e1201-e1202.

4. Murase E, Siegelman ES, Outwater EK, Perez-Jaffe LA, Tureck RW. Uterine leiomyomas: histopathologic features, MR imaging findings, differential diagnosis, and treatment. Radiographics 1999;19:1179-1197.

5. Persaud V, Arjoon PD. Uterine leiomyoma. Incidence of degenerative change and a correlation of associated symptoms. Obstet Gynecol. 1970;35:432-436.

6. Gompel C, Silverberg SG. The corpus uteri. In: Gompel C, Silverberg SG, eds. Pathology in Gynecology and Obstetrics. $4^{\text {th }}$ ed. Philadelphia, PA: Lippincott; 1994;163-283.

7. Cohen DT, Oliva E, Hahn PF, Fuller AF, Jr., Lee SI. Uterine smooth-muscle tumors with unusual growth patterns: imaging with pathologic correlation. AJR Am J Roentgenol. 2007;188:246-255.

8. Sinha R, Hegde A, Mahajan C, Dubey N, Sundaram M. Laparoscopic myomectomy: Do size, number, and location of the myomas form limiting factors for laparoscopic myomectomy? J Minim Invasive Gynecol 2008; 15:292-300.

9. Fasih N, Prasad Shanbhogue AK, Macdonald DB, Fraser-Hill MA, Papadatos D, Kielar AZ, et al. 
Leiomyomas beyond the uterus: unusual locations, rare manifestations. Radiographics. 2008;28(7):1931-48.

10. Kho KA, Nezhat C. Parasitic myomas. Obstet Gynecol. 2009;114(3):611-5.

11. Lumsden MA, West CP, Bramley T, Rumgay L, Baird DT. The binding of epidermal growth factor to the human uterus and leiomyomata in women rendered hypo-oestrogenic by continuous administration of an LHRH agonist. $\mathrm{Br} \mathrm{J}$ Obstet Gynaecol.1988;95:1299-1304.

12. Cucinella G, Granese R, Calagna G, Somigliana E, Perino A. Parasitic myomas after laparoscopic surgery: an emerging complication in the use of morcellator? Description of four cases. Fertil Steril. 2011;96(2):e90-6.

13. Pezzuto A, Serboli G, Ceccaroni M, Ferrari B, Nardelli GB, Minelli LL. Two case reports of bowel leiomyomas and review of literature. Gynecol Endocrinol. 2010;26(12):894-6.

14. Moon HS, Koo JS, Park SH, Park GS, Choi JG, Kim SG. Parasitic leiomyoma in the abdominal wall after laparoscopic myomectomy. Fertil Steril. 2008;90(4):1201.e1-2.

DOI: $10.5455 / 2320-1770$. ijrcog20130933

Cite this article as: Sreelatha S, Kumar A, Nayak V, Punneshetty S, Hanji N. A rare case of primary parasitic leiomyoma. Int $\mathrm{J}$ Reprod Contracept Obstet Gynecol 2013;2:422-4. 